\title{
The Heart of the Matter: Creating Invitational Classrooms in Online Learning
}

\author{
Sharon L. Moore ${ }^{1}$, Kerry E. Black ${ }^{2}$ \\ ${ }^{1}$ Athabasca University, ${ }^{2}$ University of Alberta \\ Canada
}

\begin{abstract}
Until fairly recently, online education was primarily located within the purview of individualized programs or distance universities. In the past decade, "online" has become common across post-secondary institutions as technology has created opportunities for connecting globally. While these opportunities can be exciting, they also pose challenges for engaging learners in meaningful ways. How can we as teachers inspire our students and be real and present in the online classroom? Based on three decades of distance and online teaching experience, my colleagues and I have learned that while online programs have proliferated and technology has moved at lightening- speed, creating invitational, collaborative online classrooms requires creative and intentional instructional strategies that differ from face-to-face education. We have learned that the teacher still matters and must use deliberate actions and strategies to help students feel part of the learning community. Teacher presence in the online classroom is a crucial aspect of dynamic learning environments. In this paper, innovative strategies (Artistic Pedagogical Technologies) for engaging students and creating invitational online classrooms will be introduced.
\end{abstract}

\section{Introduction}

Parker Palmer in his seminal work on the Courage to Teach said "we teach who we are". "I am a teacher at heart, and there are moments in the classroom when I can hardly hold the joy. When my students and I discover uncharted territory to explore, when the pathway out of a thicket opens up before us, when our experience is illumined by the lightening-life of the mind - then teaching is the finest work I know" "[1]. What an inspiration! For teachers who work in online educational environments, this idea holds the promise of something that encompasses what we believe to be the heart of the matter for teaching and learning. It suggests that teacher presence is important and necessary regardless of the type of learning environment. It is our belief that it is possible for this to occur through invitational educational learning environments.

Invitational Education as a concept originated with William Watson Purkey in the late 60's and explicated an approach to teaching and learning that focused on enhancing the self-concept of learners. Creating invitational classrooms is based on his conception of invitational theory developed as a model of professional practice ${ }^{[2]}$. "Purkey used the word invitational to mean offering something valuable and summoning cordially. An invitation is an intentional and caring act of communication designed to offer something beneficial for consideration" [3]. A basic premise of invitational theory is that "everyone and everything adds to, or subtracts from, human existence"[4]. In the educational context, this suggests that students can benefit each other through an invitation to participate in the learning environment ${ }^{[5]}$. It also means that the professor plays an important role in creating the environment where students feel safe to engage with one another and with the teacher. Palmer postulated that it is an "air of hospitality" that contributes to invitational classrooms where hospitality encompasses "receiving each other, our struggles, our newborn ideas with openness and care $^{[6] "}$.

A core assumption of invitational theory is that learning environment affects students' learning ${ }^{[7]}$ and that this holds true whether the learning environment is a face to face setting or an online classroom. Moore and Janzen ${ }^{[8]}$ in an article which portrays an invitational online classroom in a qualitative research course from the perspective of student and teacher, share examples of this. "By providing continual invitations to 'walk with me' students that may otherwise experience feelings of being 'lost' within the tenets and procedures of qualitative research, have continual opportunities to 'walk' the qualitative landscapes and mountains together with an experienced educator-guide".

The theoretical framework that underlies this approach is that of constructivism, an approach that is concerned not with transmitting knowledge but rather with engaging learners in the process of inquiry and problem solving through interacting, dialoging and negotiating. 
In online education, this may prove a little more challenging, yet wonderful opportunities exist to be creative in constructing environments that foster student success and engagement in the learning process as a means of bridging the virtual and the real ${ }^{[9]}$. In fact, technology offers ways to do this that reduce barriers for many learners with respect to time, location and scheduling. The Faculty of Health Disciplines at Athabasca University in Alberta Canada has developed their graduate programs in nursing and health studies using an underlying foundation of invitational theory. Faculty here have developed and pioneered the use of artistic pedagogical technologies (APTs) as a strategy for creating invitational online classrooms ${ }^{[10]}{ }^{[11]}$. Research conducted by Perry and Edwards ${ }^{[12]}$ found that the use of APTs in online learning facilitated interactions among teachers and learners and helped to create "an air of hospitality". In this paper, we introduce some of these strategies that can be used to facilitate the creation of invitational and engaging classrooms in online learning environments.

\section{Assumptions of Invitational Theory}

Three basic assumptions underlie invitational theory:

1. Students have the capacity for self-direction and should be treated accordingly

2. Process is as important as outcome.

3. Human beings possess untapped potential and the design of educational programs should intentionally strive to tap this potential ${ }^{[13]}$.

This is achieved through strategies that the teacher uses to interact and engage the learners in the online classroom. Invitational education provides a way of creating welcoming learning environments where students feel safe and welcome and willing to engage with each other in collaborative ways where knowledge is co-constructed. The key components of invitational theory trust, respect, optimism, care and intentionality ${ }^{[14]}$. The professor intentionally selects strategies in the online classroom that are designed to provide a welcoming environment, one that encourages participation and engagement and connection with fellow learners and the course professor.

\section{Teaching Activities and Strategies}

In an excellent book Teaching Health Professionals Online, the Melrose, Park and Perry describe several artistic pedagogical strategies ${ }^{[15]}$. (This book is available either for purchase in a paperback version or as a free (pdf) download:

http://www.aupress.ca/index.php/books/120234). We will draw on four of these to show examples of how they might be used and we encourage you to consult this textbook to see more detailed descriptions of these and other strategies.

\section{1. "Me to You" Videos}

With the evolution of computer technology, it is possible to create a simple video and within minutes post it online. "Me to You" are generally short videos (2 minute) prepared by the course professor as a means of personalizing him/herself and the course material. In a face to face class, the professor can walk in, introduce herself, review what was covered the week before, provide new insights, summaries, offer encouragement and be present with the class. In an online learning environment, "Me to You" videos offer the same opportunity. The professor can begin each new unit in the course with one of these videos and upload them to a youtube channel that can be set up specifically for that course. Generally the video is an unscripted, informal and inviting "chat" made in the professor's home office so students see the wall hanging, paintings books, whatever it is that makes their office their own. "Me to You" videos can also be used to summarize weekly sessions or topic areas. The professor can use these to acknowledge contributions of individuals, calling them by name, summarize highlights of the discussion, notice different points of view and offer insights based on the class discussions. In this way, the professor becomes real to and present with the students. When done on an ongoing basis throughout the course, they become a means of engaging with the students and help to mitigate feelings of isolation that sometimes are present in online learning.

\subsection{Photovoice}

Several years ago, Wang and Burris ${ }^{[16]}$ developed a participatory action research methodology called photovoice in which they used photographs to elicit participants experiences about health and community needs. In 2006, Dr. Beth Perry transformed this idea into an online artistic pedagogical teaching technique $^{[17]}$.

This is a strategy that we have used for quite some time in our teaching. One example of this is where a photograph, a quotation and a reflective question are used to introduce each unit in a graduate course in Advanced Qualitative Methods for Health Research $^{[18]}$. The unit is called "The Process of Data Collection", the following image is presented along with instructions for reflection; 


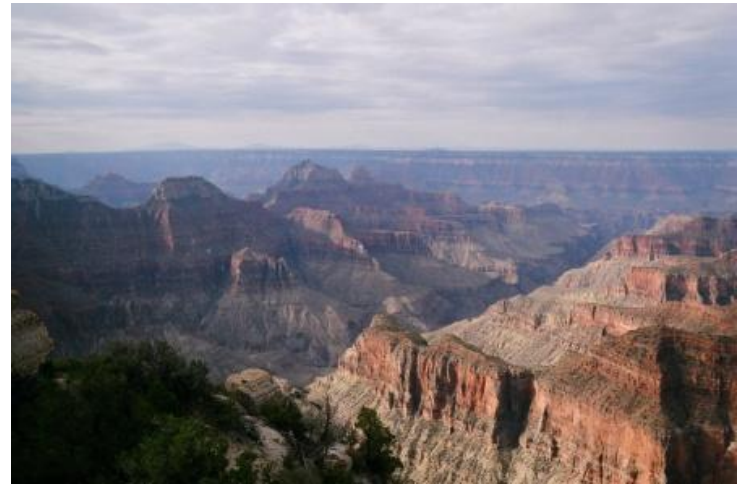

Figure 1. Photograph

(Grand Canyon, photo by Sharon Moore)

"We shall not cease from exploration and the end of all our exploring will be to arrive where we started and know the place for the first time" ${ }^{[19]}$. (T.S. Eliot, cited in Patton, 2002, p. 265)

\section{Instructions to the students:}

"The photo and the quote for this unit are selected as a way to get you to think about the meaning of data collection. We invite you to talk about this in the unit discussion forum and your understanding of what it might mean from the perspective of data”.

The students' online discussions reflect considered thought and dialogue in a deep and meaningful way as seen in just one student's comments.

"Data collection and analysis both include cycling between the whole and the part, analyzing one and then stepping to the other to view the subject from a different perspective again. One of our readings compares this to moving from interviews to analysis and back for further interviews. I repeat that description here because I think it such as perfect fit for Eliot's statement. We not only return to places and know them for the first time, but we will depart and return yet again, and find that our understanding has grown further still. The cycle is potentially all but infinite. The image of the Grand Canyon, for me, evokes a sense of the grandeur of that cyclical journal to understanding. In some ways, I feel quite small to be participating in such an overwhelming process. More importantly, Ifeel inspiration at the magnificent view and opportunity".

This example is but one of the level of dialogue that students engage in around some of the course content. The invitation to reflect on the photograph and how it relates to the topic encourages a depth of discussion that words alone do not.
A coffee forum is simply an online forum within the course that provides a place for informal discussions and sharing not usually related to the course. Students interests are often discovered and shared through what they discover about each other in their discussions of photovoice activities and sometimes groups are formed either as a result of these shared interests (e.g. a subgroup of the class who got together online because of their interest in hiking and climbing - which arose from an image of a hiker standing above the clouds). This group went on to complete their group project together because they shared a common interest.

In a recent course, one of the students shared in her introduction that she was going to have a baby during the course. When the baby was born, she posted a photo of her newborn in the coffee room. It was so much fun for all of us and offered a way to congratulate and encourage her.

The Coffee Forum is also a place where teachers can go to post encouraging or inspirational thoughts for the class. In some courses, there may be a particularly stressful week for the students and one faculty member posts a week of Hope Thoughts (one each day) for 7 days. Teachers can build a "bank" of inspirational stories, quotes and suggestions that they can draw upon to intentionally inspire and motivate students. Teachers can try to monitor the online class atmosphere and intentionally post encouragement or motivating comments when it seems appropriate to do so.

\subsection{Parallel Poetry}

"Emotion is difficult to express or convey online, but poetry provides a vehicle for sharing feelings within the limitation of words. Reflective or parallel poetry is a useful teaching tool in helping students achieve outcomes in the affective domain that may involve a change in attitudes or beliefs and in helping learners and instructors to express feelings and emotional experiences.

In parallel poetry as seen in the example below, the instructor provides an example poem on a topic related to the course content (Haikius, odes, limericks, narratives etc. have been useful for this APT). Students are invited to create their own poem (a parallel poem) after reading the example poem"[20].

\author{
Teacher Poem \\ On Caring... \\ It is difficult \\ To put into precise words, \\ What it means to care. \\ Is it giving, not taking? \\ Is it listening, not talking? \\ Is it bending, not standing strong?
}

\section{Student Poem}




\section{On Caring...}

What does it mean to care?

It is giving and taking, at just the right moments. It is listening and talking, in perfect balance.

It is bending and standing strong, strong enough for two.

(used with permission from Melrose, Park \& Perry, 2013, p. 56).

In this activity, it is easy for the student to see and to feel the presence of the teacher and to connect at an emotional level. This strategy can be used to in a variety of ways.

Three additional strategies that we have used to foster invitational classrooms are described below; apprecograms, the use of media and metaphors as instructional tools.

\subsection{Apprecograms}

In a recent faculty meeting, Perry described an activity that she called "Apprecograms' (personal communication, January 25, 2018). Apprecograms are short notes that a teacher writes individually and emails to each student in the class that let the students know something you appreciate about them. Each note is crafted specially for a particular student, calling them by name and noting an appreciation. One of the authors tried this in a recent course and all but one student replied to the teacher how much they appreciated the thought and they each went on to elaborate on something that was mentioned in their own personal note. One student emailed the teacher and said "what a wonderful way to start my day. Thank you!"

Another student expressed his gratitude in response to an appreciation about his passion for the topic he was writing about. He explained how passionate he was and that he tried to live what he talked about as a leader in order to create stronger organizations. This strategy is not only of benefit for the students however. The teacher found herself focused on looking for something positive to comment on for each student and while doing this, realized that it was possible to discover something to appreciate even in students who are struggling.

\subsection{Invitation to Reflection through Multimedia}

Employed as a strategy to facilitate students understanding of the dimensions of qualitative research, a short video The Paths I've Walked with images taken from around the world is set to a piece of music and linked in the students online course. The students are asked to view the video and respond to questions in two stages. The first set of questions asks the students to reflect on what they experienced in watching the video and to post their reflections in the discussion forum:

What is being conveyed in the images?

What did you see?, What did you hear?

What meaning do you take from this video?

How did it impact you?

How do you think your own values and beliefs influenced your understanding?

After the students have had some time to read and reflect on their classmates responses, they are asked to consider some further questions:

As you think about and read other responses, what are you noticing?

What insights might this offer about qualitative research?

What are some of the dimensions of qualitative research that might become visible through this activity?

The students' responses and dialogue around these questions provide wonderful opportunities for the teacher to engage the class in rich dialogues about many important aspects of the nature and dimensions of qualitative research. They begin to see and experience concepts such as the multidimensionality, contextuality and subjectivity of qualitative research. Their conversations take on life in a way that just reading about these concepts does not generate and they offer a variety of ways for the teacher to be present with, and to engage with the students in meaningful ways.

\subsection{Use of Metaphor}

Metaphors can be powerful teaching tools. In a recent graduate course (which was the last program course for a group of students), the teacher (one of the authors) invited the students at the beginning of the course to choose a photograph as a metaphor to represent where they were in their educational journeys as they started this final step in their program of studies. They were invited to share their photograph and their reflections with the class. This was not a required activity but all but one student chose to participate. Their photographs and responses to those photographs reflected thoughtful consideration and a wide range of responses. For many, this activity really brought home the significance of the ending of a major commitment of time, energy and dedication. For some, their photographs suggested a climb that was still facing them for the remainder of the semester. At the end of the semester, the students can once again be invited to choose another photograph to represent where they have come to in their educational journeys. It will be interesting for them and for their teacher to relook at from whence they have come. 


\section{Weaving Connections: The Heart of the Matter}

Regardless of where you teach or in what kind of environment, "TEACHING MATTERS". We believe as Parker Palmer notes that "good teaching cannot be reduced to technique. It comes from the identify and integrity of the teacher" [21]. As faculty who teach in online environments, we have seen and experienced the joy that comes from teaching and from engaging with students in meaningful learning experiences. We have shared in their excitement as they report on how their learning has been transformational. We have tried many learning activities and experimented with artistic pedagogical technologies. Some have worked better than others but there are great personal rewards as teachers in the quest for strategies that facilitate our teaching and learning with students. In online teaching environments, despite the fact that we are not face to face with the students, we have found that it is still possible, in fact it is crucial to be present and to be engaged in the classroom. Our work is challenging, exciting and meaningful as we see the intersection of what we teach, how we teach, and how students are engaged in their learning. It is at this intersectionality that the learning experience deepens according to Brown[22]. This kind of teaching, requires not only strategies however but an ongoing examination of self as teacher. It reminds us that we always seem to be in the process of becoming better. Parker Palmer continues to inspire us to keep trying to be better teachers. He says that "Good teachers possess a capacity for connectedness. They are able to weave a complex web of connections among themselves, their subjects and their students so that students can learn to weave a world for themselves. The methods used vary widely ... The connections made by the teachers are not held in their method, but in their heartsmeaning heart in the strictest sense, as the place where intellect and emotion and spirit will converge in the human self'[23].

By creating invitational classrooms through intentionally choosing activities and strategies that help us connect and engage with students, we can establish alive and vibrant online classrooms built on trust and respect where students are excited about and engaged in their learning journeys. A good teacher makes a difference to learners and to the learning process itself.

In the words of our colleagues Melrose, Perry and Park we challenge you (as we continue to challenge ourselves) to "take deliberate steps enhance the effectiveness of your online courses. Examine how your own intellect, emotion and spirit come together to make you the teacher you are and the teacher you will become' [24]. As you do this, you will come to know and experience "the heart of the matter" in teaching and learning.

\section{Acknowledgements}

We would like to thank our colleagues and mentors who have inspired us to try new strategies and to truly strive to be teachers who make a difference in the lives of our students. Our gratitude goes out to exemplary educators Sherri Melrose, Beth Perry, Caroline Park, and Margaret Edwards who have pioneered the development and use of Artistic Pedagogical Technologies and many others who inspired us as in our educational journeys.

\section{References}

[1] P. Palmer, The Courage to Teach: Exploring the Inner Landscape of a Teacher's Life, Jossey-Bass, San Francisco, 2007, (p. 1).

[2] D.E. Shaw, B.L. Siegel, and A. Schoenlein, "The Basic Tenets of Invitational Theory and Practice: An Invitational Glossary" Journal of Invitational Theory and Practice, 191), 2013, pp. 30-42.

http://files.eric.ed.gov/fulltext/EJ1022547.pdf

[3] S. Melrose, C. Park, and B. Perry, Teaching Health Professionals Online: Frameworks and Strategies, AU Press, Athabasca, AB. Canada (2013).

http://www.aupress.ca/index.php/books/120234

[4] W.W. Purkey, "An Introduction to Invitational Theory, Journal of Invitational Theory and Practice, 1,1992, pp. 5-15, Retrieved from: http://www.invitationaleducation. net/journal/JITP\%20Vol\%2081.pdf

[5] W.W. Purkey and J.M. Novak, "An Introduction to invitational theory", 2015, Retrieved from: https://www.invitationalEducation.net/docs/

[6] P. Palmer. To know as we are known: Education as a spiritual journey. Harper, San Francisco, 1993, p. 74.

[7] M. Haigh, "Invitational Education: Theory, Research and Practice", Journal of Geography in Higher Education, 35(2), 2011, pp. 299-309, doi.org/10.1080/03098265.2011.554115

[8] S.L. Moore, and K.J. Janzen. Walk with Me. A Qualitative Research Journey, Academic Exchange Quarterly, 16(3), (2012), Rapid Intellect, http://rapidintellect.com/AEQweb/cho5176.htm

[9] K. J. Janzen, B. Perry, and M. Edwards. “Aligning the Quantum Perspective of Learning to Instructional Design: Exploring the Seven Definitive Questions", The International Review of Research in Open and Distance Learning, 12(7), Athabasca University, 2011, pp. 56-73. http://www.irrodl.org/ 
index.php/irrodl/issue/view/49

[10] B. Perry, and M. Edwards. "Creating an 'Invitational Classroom' in the Online Educational Milieu", American Journal of Health Sciences, 3(1), The Clute Institute, 2012, pp. 7-16. https://doi.org/10.19030/ajhs.v3i1.6747

[11] S. Melrose, C. Park, and B. Perry, Teaching Health Professionals Online: Frameworks and Strategies, AU Press, Athabasca, AB. Canada. (2013). http://www.aupress.ca/index.php/books/120234

[12] B. Perry, and M. Edwards. "Creating an 'Invitational Classroom' in the Online Educational Milieu", American Journal of Health Sciences, 3(1), The Clute Institute, 2012, pp. 7-16. https://doi.org/10.19030/ajhs.v3i1.6747

[13] W.W. Purkey and J.M. Novak, Fundamentals of invitational education, International Alliance for Invitational Education, Georgia, 2008.

[14] D.E. Shaw, B.L. Siegel, and A. Schoenlein, "The Basic Tenets of Invitational Theory and Practice: An Invitational Glossary" Journal of Invitational Theory and Practice, 191), 2013, pp. 30-42.

http://files.eric.ed.gov/fulltext/EJ1022547.pdf

[15] S. Melrose, C. Park, and B. Perry, Teaching Health Professionals Online: Frameworks and Strategies, AU Press, Athabasca, AB. Canada. (2013). http://www.aupress.ca/index.php/books/120234

[16] C. Wang and M. Burris. "Photovoice: Concept, Methodology, and Use for Participatory Needs Assessment", Health Education Behavior, 24, 1997, pp. 369-387. DOI: 10.1177/109019819702400309

[17] B. Perry, Using Photographic Images as an Interactive Online Teaching Strategy, The Internet and Higher Education, 9(3), 2006, pp. 229-240. DOI.org/10.1016/j.iheduc.2006.06.008

[18] S.L. Moore, Advanced Methods for Qualitative Health Research (MHST 712 Online Graduate Course), Athabasca, AB. Canada, 2017.

[19] M. Patton, Qualitative research and evaluation methods (3rd ed.). Sage Publications, Thousand Oaks, CA, 2002.

[20] S. Melrose, C. Park, and B. Perry, Teaching Health Professionals Online: Frameworks and Strategies, AU Press, Athabasca, AB. Canada. (2013). http://www.aupress.ca/index.php/books/120234
[21] P. Palmer, The Courage to Teach: Exploring the Inner Landscape of a Teacher's Life, Jossey-Bass, San Francisco, 2007, p. 10.

[22] H. Brown. "Moments of Intersectionality: Moving Invitational Theory into Practice through a Constructivist Approach", Journal of Invitational Theory and Practice, 22, Jan. 2016, pp. 48-67, ISSN: 10606041.

[23] P. Palmer, The Courage to Teach: Exploring the Inner Landscape of a Teacher's Life, Jossey-Bass, San Francisco, 2007, p. 11.

[24] S. Melrose, C. Park, and B. Perry, Teaching Health Professionals Online: Frameworks and Strategies, AU Press, Athabasca, AB. Canada. http://www.aupress.ca/index.php/books/120234 